Pesq. Vet. Bras. 31(1):10-16, janeiro 2011

\title{
Comparação entre a imunidade induzida em bovinos vacinados com bacterinas polivalentes comerciais e uma monovalente experimental ${ }^{1}$
}

\author{
Rogério O. Rodrigues ${ }^{2,3^{*}}$, Geder P. Herrmann ${ }^{4}$, Marcos B. Heinemann², \\ Andrey P. Lage ${ }^{2}$, Luciano B. Lopes ${ }^{2,5}$ e Elvio C. Moreira ${ }^{2}$
}

\begin{abstract}
Rodrigues R.O., Herrmann G.P., Heinemann M.B., Lage A.P., Lopes L.B. \& Moreira E.C. 2011. [Comparison between immunity induced in cattle vaccinated with commercial polyvalent bacterins and one experimental monovalent.] Comparação entre a imunidade induzida em bovinos vacinados com bacterinas polivalentes comerciais e uma monovalente experimental. Pesquisa Veterinária Brasileira 31(1):10-16. Departamento de Medicina Veterinária Preventiva e Epidemiologia, Escola de Veterinária, Universidade Federal de Minas Gerais, Belo Horizonte, MG 30123-970, Brazil. E-mail: rogerrodriguesvet@ gmail.com

The study evaluated the induction of antibody production against ten bacterins, nine polyvalent and one experimental monovalent to serovar Hardjo strain Norma. An indirect enzyme linked immunosorbent assay (ELISA) was developed using anti-lgG conjugate to measure total levels of IgG class antibodies conferred by bacterins using three different strains: Hardjoprajiitino, Norma and Hardjo-bovis. Microscopic Agglutination Test (MAT) was also used to measure immunoglobulin levels of the same strains. Variable ELISA titers were induced by the tested bacterins. The MAT titers found showed lower intensity and shorter duration, indicating the need to cellular control in further standardization of these vaccines. Based on results of this study, the monovalent bacterin showed best performance.
\end{abstract}

INDEX TERMS: Leptospira, vaccine, cattle, immunoglobulin.

RESUMO.- O presente estudo avaliou a indução da produção de anticorpos contra Leptospira spp.por dez bacterinas, sendo nove polivalentes e uma monovalente experimental para a sorovariedade Hardjo amostra Norma. A concentração celular foi controlada e utilizou-se adjuvante de emulsão óleo em água. Um ensaio imunoenzimático (ELISA) indireto foi desenvolvido utilizando-se conjugado anti-lgG total para mensurar os níveis de anticorpos da classe IgG conferido pelas bacterinas utilizando três amostras diferentes: Hardjoprajitino, Norma e Hardjo-bovis. Paralelamente

\footnotetext{
${ }^{1}$ Recebido em 19 de fevereiro de 2010.

Aceito para publicação em 4 de setembro de 2010

2 Departamento de Medicina Veterinária Preventiva, Escola de Veterinária, Universidade Federal de Minas Gerais (UFMG), Av. Antônio Carlos 6627, Cx. Postal 567, Belo Horizonte, MG 30123-970, Brasil.

${ }^{3}$ Departamento Ciências da Saúde, Universidade Vale do Rio Doce, Rua Israel Pinheiro 2000, Cx. Postal 295, Governador Valadares, MG 35020220, Brasil .*Autor para correspondência: rogerrodriguesvet@gmail.com

${ }^{4}$ Departamento Microbiologia e Parasitologia, Universidade Federal de Santa Maria (UFSM), Camobi, Santa Maria, RS 97105-900, Brasil.

${ }^{5}$ Embrapa-Empresa Brasileira de Pesquisa Agropecuária, Centro de Pesquisa da Empaer-MT, Estrada Ângela, Km 5, Cx. Postal 329, Sinop, MT 78550-000, Brasil.
}

foi utilizado também o Teste de Soroaglutinação Microscópica (SAM) para mensurar os níveis de anticorpos contra as mesmas amostras. Encontraram-se títulos variáveis entre as bacterinas de acordo com o teste ELISA. Os títulos no SAM foram de pouca intensidade e de curta duração indicando a necessidade de controle celular para uma posterior padronização destes produtos. Com base nos resultados encontrados no presente estudo, a bacterina monovalente foi a que apresentou melhor desempenho.

TERMOS DE INDEXAÇÃO: Leptospira, vacina, bovinos, imunoglobulinas.

\section{INTRODUÇÃO}

A leptospirose, nos bovinos, causa consideráveis perdas econômicas em decorrência de distúrbios reprodutivos, como repetições de cio, infertilidade, abortamentos, natimortalidade, bezerros prematuros, nascimento de bezerros fracos, além de decréscimo na produção de leite e de carne (Moreira 1994, Cortez et al. 2006).

Os estudos sorológicos para determinação da proporção de animais sororreatores para a leptospirose têm sido realizados no Brasil, particularmente em animais de pro- 
dução e companhia, as relações entre sorovariedade de Leptospira spp. e os hospedeiros preferenciais mais frequentes variam segundo a região, no entanto de uma forma geral os registros predominantes em bovídeos são das sorovariedades Hardjo, Wolffi e Hebdomadis (Vasconcellos 1997, Favero et al. 2001, 2002).

Os resultados obtidos dependem das coleções de antígenos empregadas e dos critérios adotados para a interpretação dos exames, no entanto, as proporções de positivos têm sido elevadas e variáveis de $15-66 \%$ em bovinos (Cordeiro et al. 1975, Oliveira 1977, Moreira et al. 1979, Giorgi et. al. 1981, Doria et al. 1982, Brod et al. 1995, Lilenbaun \& Santos 1996, Vasconcellos et al.1997, Favero et al. 2001, Homem et al. 2001).

No Brasil, várias sorovariedades de Leptospira spp. tem sido identificados nos rebanhos bovinos, mas a sorovariedade mais frequentemente encontrado é a Hardjo, que esta intimamente implicada com problemas reprodutivos no gado bovino (Moreira 1994, Favero et al. 2001, Araújo et al. 2005, Lage et al. 2007).

A alternativa mais eficaz para controlar ou erradicar as leptospiroses em bovinos é o uso de vacina elaborada com a sorovariedade específica prevalente na propriedade. No Brasil, a maioria das vacinas disponíveis no mercado não atende a esse pré-requisito (Araujo et al. 2005). Estudos têm demonstrado a falha na proteção completa com a sorovariedade Hardjo e entre sorovariedades da espécie Leptospira borgpetersenii (Bolin et al. 1989).

A amostra de referência Norma foi isolada em 1993, no Estado de Minas Gerais, Brasil e tipificada por anticorpos monoclonais e pela reação em cadeia pela polimerase (PCR) como L. interrogans sorovariedade Hardjo, genótipo Hardjoprajitino (Moreira 1994).

Devido às diferenças encontradas nos resultados do Laboratório de Zoonoses entre a sorovariedade Hardjoprajitino e a sorovariedade Hardjoprajitino amostra Norma detectando o maior número de animais positivos. Estas diferenças entre as amostras Norma e Hardjoprajitino já haviam sido observadas antes, com maior ou menor intensidade em outras populações de bovinos e ovinos em outros Estados do Brasil (Moreira 1994, Hermann et al. 2004, Araújo et al. 2005, Lage et al. 2003).

O fato da resposta imunológica ser de pouca intensidade e específica para cada sorovariedade faz das vacinas comerciais uma medida profilática muitas vezes ineficiente (Hanson 1997, Faine et al. 1999). Existe a tendência dos animais que já estão infectados e que ainda não foram tratados somente vacinados, tornarem-se portadores destes microrganismos (Srivastava 2006).

O presente trabalho teve como objetivo a comparação dos títulos de anticorpos anti-Leptospira spp. para a sorovariedade Hardjo em bovinos imunizados com vacinas polivalentes disponíveis no mercado brasileiro e com uma vacina monovalente experimental pelo do Teste de Soroaglutinação Microscópica (SAM) e pelo ensaio imunoenzimático (ELISA) para amostras homólogas bem como heterólogas (Hardjoprajiitino, Norma e Hardjo-bovis).

\section{MATERIAL E MÉTODOS}

\section{Grupos experimentais}

Foram utilizados 99 bovinos da raça holandesa provenientes de um mesmo rebanho, com idades entre 24 e 48 meses, divididos em 11 grupos com nove bovinos em cada grupo, sendo que todos os bovinos na época da primovacinação eram sorologicamente negativos para leptospirose pelo Teste de Soroaglutinação Microscópica (SAM). Estes animais foram estudados durante 12 meses (testes mensais) para verificação de circulação de Leptospiras spp. em infecção prévia.

As vacinas foram adquiridas em representantes credenciados pelos fabricantes, dentro do prazo de validade estabelecido. O esquema de vacinação, assim como o local de aplicação, intramuscular ou subcutâneo. foi realizado de acordo com as especificações de cada fabricante (todos os fabricantes recomendam o mesmo esquema), ou seja, duas doses intervaladas de 30 dias e uma revacinação seis meses após a última dose. Por razões éticas os nomes comerciais foram codificados pelas letras A, B, C, D, E, G, H, I, J e K.

As vacinas foram administradas nas doses de $2 \mathrm{~mL}$ para a vacina $\mathrm{J}$, de $3 \mathrm{~mL}$ paras as vacinas $A, E$ e K, e de $5 \mathrm{~mL}$ paras as vacinas $B, C, D, G, H$, e I. Para o controle negativo, vacina $F$, foram administradas doses de $5 \mathrm{~mL}$ de salina estéril. As vacinas foram administradas nos dias 0,30 e 210 .

Realizaram-se coletas mensais (com intervalos fixos de 30 dias entre as coletas) de sangue pela punção da veia jugular do dia 0 ao dia 420 , perfazendo quinze coletas.

\section{Soroaglutinação microscópica}

A técnica do SAM foi realizada segundo Galton et al. (1965) e Cole et al. (1973) com modificações. Os soros foram diluídos a 1/5 e a partir daí foram feitas diluições seriadas de razão 2 , considerando-se título positivo a recíproca da maior diluição com $50 \%$ ou mais de Leptospira spp. aglutinadas, sendo o título máximo alcançado de 1280 . Os antígenos utilizados foram das amostras Hardjoprajitino, Norma e Hardjo-bovis da sorovariedade Hardjo, cultivados em meio EMJH modificado por Ellinghausen e McCullough (1965).

\section{ELISA}

O ensaio imunoenzimático (ELISA) foi realizado utilizando-se antígenos das amostras Hardjoprajitino, Norma e Hardjobovis cultivados durante 14 dias em meio EMJH. Estes antígenos foram sonicados com uma frequência de $80 \mathrm{kHz}$, durante 2 min com pulsos de $10 \mathrm{~s}$. A concentração proteica foi dosada pelo método de Lowry et.al. (1951). O antígeno foi diluído em tampão (carbonato/bicarbonato) de ligação $\left(\mathrm{pH} 9,6 / \mathrm{Na}_{2} \mathrm{CO}_{3}+\right.$ $\mathrm{NaHCO}_{3}+\mathrm{H}_{2} \mathrm{O}$ ) em uma concentração de $0,5 \mathrm{mg} / \mathrm{mL}$. As placas foram sensibilizadas com $100 \mathrm{~mL}$ por poço desta diluição por $18 \mathrm{~h}$ a temperatura de $4^{\circ} \mathrm{C}$. As placas foram lavadas com PBS (pH 7,4/NaCl $+\mathrm{NaHPO}_{4}+\mathrm{KH}_{2} \mathrm{PO}_{4}$ ) Tween 20 a $0,05 \%$ por três vezes e posteriormente as placas foram bloqueadas durante $1 \mathrm{~h}$ com solução de bloqueio (caseína 2\% em PBS) e lavadas novamente por três vezes (PBS pH 7.2/0,05\% Tween 20) os soros então foram diluídos em tampão de incubação (PBST 0,05\% com 0,025\% de caseína) e ensaiados em duplicata na diluição $1 / 100$ e incubados durante $2 \mathrm{~h}$. Em todas as placas foram acrescentados, em quadruplicata, soros controles positivos e negativos diluídos na mesma diluição, estes foram previamente selecionados pelo SAM. Estas placas foram novamente lavadas, com a solução de lavagem e então foi adicionado o conjugado ovino anti-lgG total bovino diluído 
1/5000 em PBST 0,05\% e incubado durante uma hora. O conjugado foi produzido segundo a metodologia preconizada por Avrameas \& Ternynck (1971) e então titulado para estabelecer a diluição de trabalho.

As placas foram então novamente lavadas e acrescentados o substrato (o-Phenylenediamine [1,2-Benzenediamine] OPD) em tampão citrato (pH 5,0/Ácido Cítrico [2-hidroxi-1,2,3propanotricarboxílico] $+\mathrm{Na}_{2} \mathrm{HPO}_{2}$ ) acrescentando-se peróxido de hidrogênio $\left(\mathrm{H}_{2} \mathrm{O}_{2}\right)$, durante 20 min. A reação foi interrompida com solução de $\mathrm{H}_{2} \mathrm{SO}_{4}$ a $1 \mathrm{M}$. A leitura foi feita em leitor de ELISA BIO-RAD ${ }^{5}$ (168-1002 Modelo 680) e os resultados expressos de acordo com o quociente Amostra/Positivo (A/P), obedecendo a seguinte fórmula:

$$
A / P=\frac{\overline{X A}-\overline{X N}}{\overline{X P}-\overline{X N}}
$$

Onde,

$\bar{X}_{\mathrm{A}}=$ Média da absorvância a $492 \mathrm{~nm}$ da duplicata da amostra.

$\bar{X}_{\mathrm{P}}=$ Média da absorvância a $492 \mathrm{~nm}$ da duplicata do soro padrão positivo.

$\bar{X}_{\mathrm{N}}=$ Média da absorvância a $492 \mathrm{~nm}$ da duplicata do soro padrão negativo.

\section{Produção da bacterina monovalente}

A amostra Norma, sovariedade Hardjo, foi cultivada em $E M J H^{6}$, enriquecido com a fração $V$ de albumina bovina, durante 14 dias a temperatura de $29^{\circ} \mathrm{C}$. O crescimento foi monitorado semanalmente e feito a contagem em câmara de Petroff-Hausser. Ao final da segunda semana, a cultura apresentou uma densidade $1 \times 10^{9}$ células $/ \mathrm{mL}$. As bactérias foram inativadas com formalina a $1 \%$ e monitorada com antissoro homólogo no SAM. A presença de Leptospiras spp. vivas foi verificada por meio de sub-cultivos em meio EMJH durante 4 semanas. Posteriormente, a vacina foi adsorvida em um adjuvante de emulsão óleo em água (Emulsigen ${ }^{\circledR 7}$ ) na concentração de $8 \%$ e vermelho fenol a $0,01 \%$ foi acrescentado como indicador de $\mathrm{pH} 7,2$. Esta bacterina foi denominada de vacina $\mathrm{G}$. A partida final foi previamente avaliada em relação à pureza e inocuidade, conforme normas preconizadas pelo United States Departament of Agriculture (1976) e OIE (2001).

A prova de esterilidade foi realizada em uma alíquota da partida que foi semeada em Agar Sangue a 5\%, caldos Tioglicolato de Sódio ${ }^{8}$, Brain Heart Infusion ${ }^{9}$, Tryptic Soy Broth ${ }^{10}$ e Agar Sabouraud ${ }^{11}$.

O produto final (bacterina) foi testado para inocuidade; uma dose de $5 \mathrm{~mL}$ foi aplicada em cinco bezerros de seis meses de idade para testar a segurança contra reações adversas.

Para comparação das médias dos títulos obtidos pelo teste de SAM, os resultados foram convertidos em logaritmo para que a distribuição dos resíduos se aproximasse da distribuição normal segundo a curva de distribuição de Gauss. A partir dos resultados encontrados pelo teste de ELISA, as médias aritméticas foram obtidas pelos valores de densidades ópticas. Os dados foram avaliados por análise de variância e pelo teste de médias de Dunn ou pelo teste de Kruskal-Wallis, quando apropriado, empregando-se um erro á de 0,05 (Sampaio 1998).

\section{RESULTADOS}

As Figuras 1 e 2 demonstram, respectivamente, para o Elisa e o SAM, utilizando a amostra Norma, os resultados das comparações de médias entre as bacterinas nos dias em que houve títulos significantes. A tendência do comportamento das vacinas com a utilização dos antígenos

\footnotetext{
${ }^{5}$ Bio-Rad Laboratories, 4000 Alfred Nobel Drive, Hercules, CA 94547, USA.

${ }^{6}$ Difco Laboratories, Voigt Global Distribution, 48238, P.O. Box 1130, Lawrence, KS 66044-8130, USA.

7 Emulsigen ${ }^{\circledR}$, MVP Laboratories, 4805 G Street, Omaha, NE 681171414, USA.

${ }^{8}$ Becton Dickison, 7 Loveton Circle, Sparks, MD 21152, USA.

${ }^{9}$ Becton Dickison, 7 Loveton Circle, Sparks, MD 21152, USA.

10 Difco Laboratories, Voigt Global Distribution, , 48238, P.O. Box 1130, Lawrence, KS 66044-8130, USA

${ }^{11}$ Becton Dickison, 7 Loveton Circle, Sparks, MD 21152, USA.
}

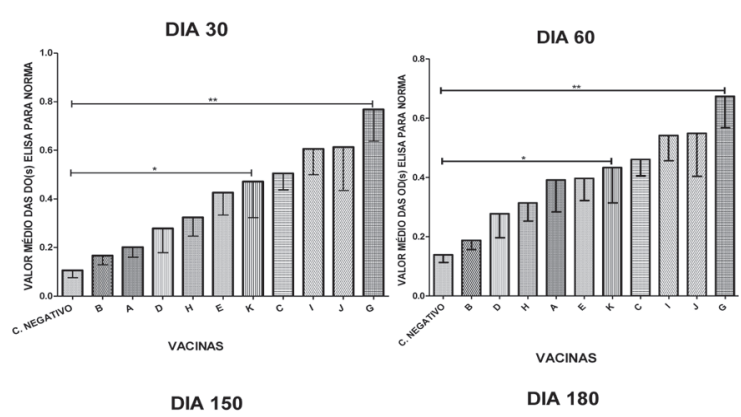

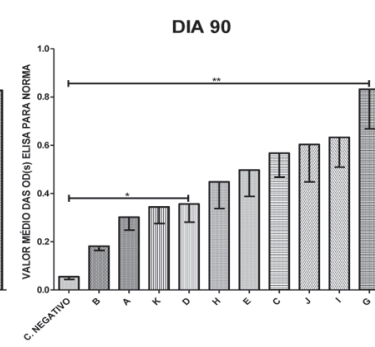

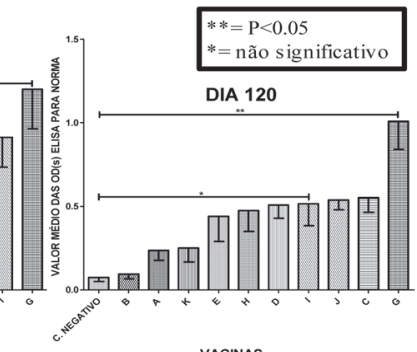

DIA 270
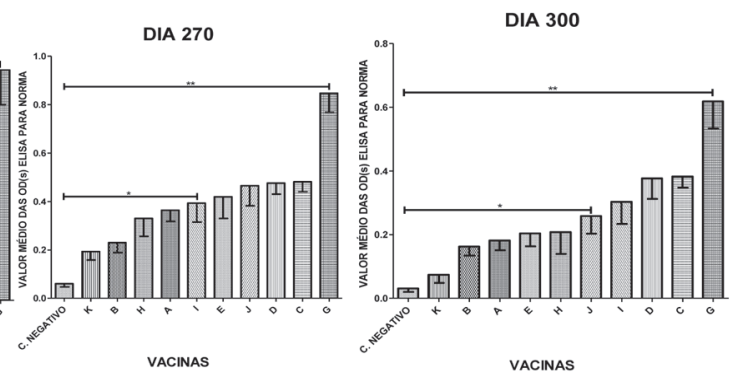

Fig.1. Valores de densidades ópticas para as bacterinas testadas pelo ELISA utilizando-se a amostra Norma da sorovariedade Hardjo nos dias 30,60,90,120,150,180,270 e 300 após a vacinação que obtiveram diferença significativa em pelo menos um grupo diferindo do controle negativo. 

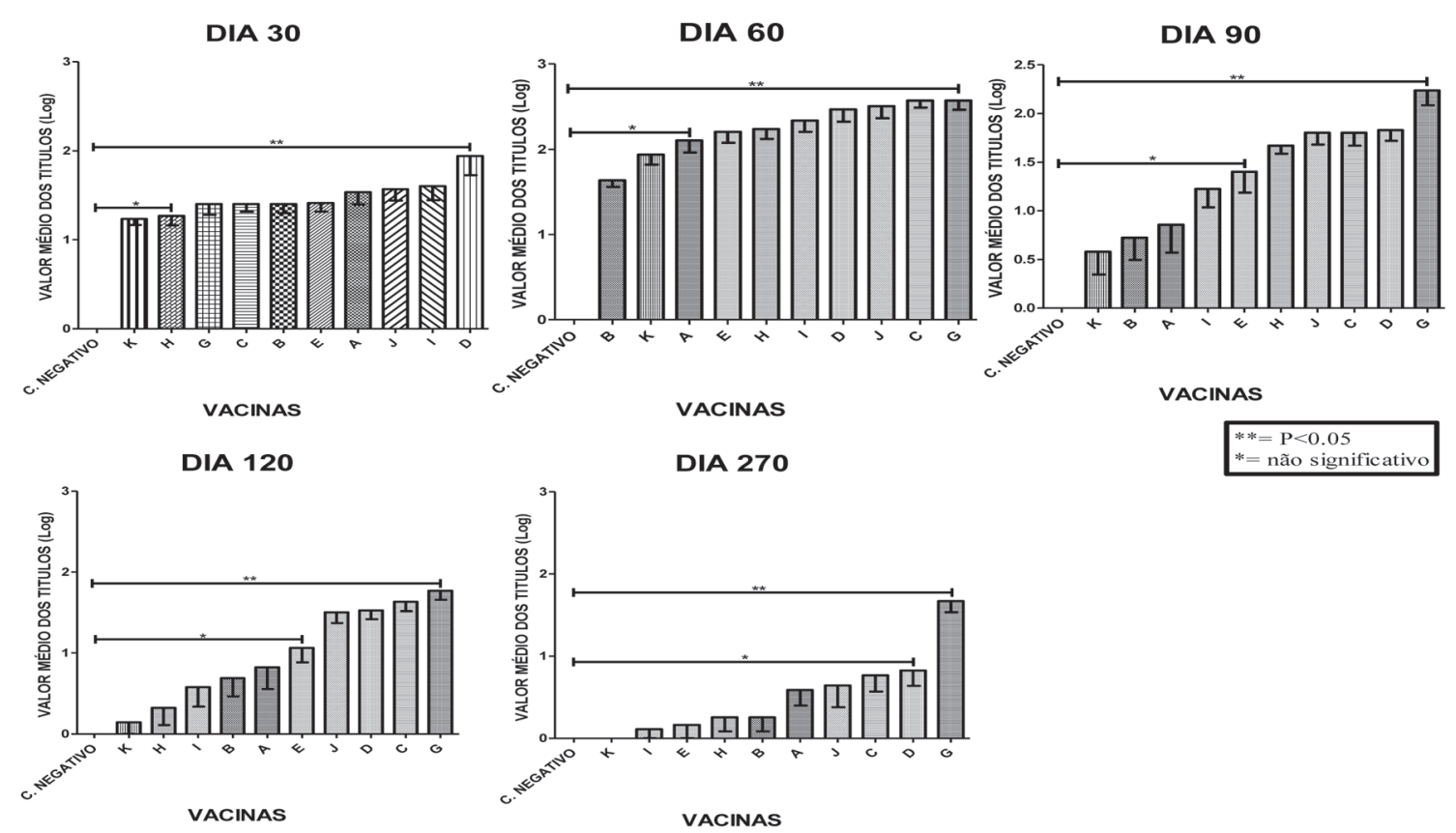

Fig.2. Valores de médias de títulos para as bacterinas testadas pelo SAM utilizando-se a amostra Norma da sorovariedade Hardjo nos dias 30,60,90,120,e 270 após a vacinação que obtiveram diferença significativa em pelo menos um grupo diferindo do controle negativo.

de Hardjoprajitino e Hardjo-bovis foi semelhante (dados não mostrados). Não houve diferenças significativas entre os títulos no ELISA e no SAM nos dias após o dia 300 e 270, respectivamente.

As médias aritméticas das densidades ópticas nos ELISA segundo os tempos de coleta demonstraram que os dias $30,60,90,120,150,180,270$ e 300 produziram títulos estatisticamente diferentes. As médias geométricas dos títulos do SAM também revelaram que os dias 30, $60,90,120$ e 270 produziram títulos estatisticamente diferentes (Fig.1 e 2).

Comparando-se às médias aritméticas das densidades ópticas para cada sorovariedade testadas pelo ELISA indireto (Quadro 1), verificou-se que a sorovariedade que obteve maior média foi a Hardjo-bovis, mas essas não diferiram estatisticamente das encontradas para a amostra Norma. A sorovariedade Hardjo foi a que demonstrou pior desempenho em relação à amostra Hardjo-bovis. E quando as médias dos logaritmos de títulos de cada sorovariedade testada pelo SAM foram comparadas (Quadro 1),

Quadro 1. Médias das densidades óticas do ELISA e dos logaritmos dos títulos do SAM de todas as bacterinas para as amostras Hardjoprajitino, Norma e Hardjo-bovis da sorovariedade Hardjo de Leptospira spp.

\begin{tabular}{ccc}
\hline Amostra & $\begin{array}{c}\text { Média das densidades } \\
\text { óticas do ELISA }\end{array}$ & $\begin{array}{c}\text { Média dos logaritmos } \\
\text { dos títulos do SAM }\end{array}$ \\
\hline Hardjoprajitino & $0,2360^{\mathrm{a}}$ & $0,2805^{\mathrm{a}}$ \\
Norma & $0,2477^{\mathrm{ab}}$ & $0,4181^{\mathrm{b}}$ \\
Hardjo-bovis & $0,3099^{\mathrm{b}}$ & $0,4951^{\mathrm{b}}$
\end{tabular}

*Valores com letras diferentes dentro da mesma coluna diferem entre si $(P<0,05)$. verificou-se que o sorovariedade Hardjo foi a que demonstrou melhor desempenho em relação à amostra Norma, mas não diferiu estatisticamente da amostra Hardjo-bovis.

\section{DISCUSSÃO}

Um dos primeiros passos na confecção de uma vacina anti-leptospira é a correta seleção e caracterização das amostras a serem utilizadas na sua formulação (Levett 2001, Faine 1999). A Associação Americana de Saúde Animal (USAH 1976) no Comitê de Leptospirose recomenda a fabricação e a utilização de uma bacterina monovalente para as sorovariedades Hardjo e outra para Grippotyphosa, além de uma polivalente contendo os sorovariedades Pomona, Hardjo e Grippotyphosa levando em consideração as taxas de bovinos sororreagentes naquele país (Hanson et al. 1972).

O presente trabalho desenvolveu uma bacterina monovalente utilizando a sorovariedade Hardjo amostra Norma, pelo fato desta ser um isolado brasileiro e também por ser a sorovariedade mais prevalente no país (Moreira 1994, Hermann et al. 2004, Araújo et al. 2005, Lage et al. 2007, Chiareli et al. 2008), e comparou-a com as bacterinas existentes no mercado brasileiro.

Soros coletados de bovinos vacinados após a revacinação geralmente produzirão resultados negativos quando testados com a SAM, entretanto o animal pode resistir à exposição natural de campo (Hanson et al., 1972), o que pode ser verificado neste trabalho considerando-se os valores das médias aritméticas das densidades ópticas dos ELISA. Uma avaliação válida da resposta imune deve incluir um teste como o teste de proteção passiva em hamsters e os ensaios imunoenzimáticos, entre outros, que são capazes de 
mensurar a classe IgG de anticorpos (Huhn et al. 1970).Contrariando os achados de Arduino et. al. (2009) que avaliando estes produtos comerciais utilizando o SAM relatou altos níveis de anticorpos aglutinantes para a sorovariedade Hardjo, podendo este não ter significado em termos de neutralização de Leptospira spp. em uma eventual infecção.

Os animais testados não apresentaram uma mesma intensidade de resposta de anticorpos aglutinantes e neutralizantes detectáveis pela SAM e pelo ELISA contra as sorovariedades testadas, quando consideradas as médias aritméticas e as médias geométricas dos logaritmos dos títulos de anticorpos. Siddique \& Shah (1990) discutem que as vacinas não induzem uma mesma resposta sorológica contra todos as sorovariedades nelas contidas, podendo isso ocorrer devido a uma diferença na concentração antigênica final, ou pela supressão da resposta antigênica causada por uma sorovariedade sobre outra. O poder imunogênico segundo a amostra utilizada também deve ser levado em consideração, devido ao fato de que existem diferenças entre elas (Bolin et al. 1989, Bolin et al. 1991, Tabata 2002). De fato, Bolin et al. (1991) referem que o aumento da massa antigênica da amostra Hardjoprajitino em uma vacina pode aumentar a antigenicidade e, consequentemente, a proteção conferida pela mesma. Resultados verificados pelo presente trabalho e também demonstrado por Favero et al (1997).

Vacina de células inteiras com sorovariedade Hardjo é um fraco imunógeno que produz imunidade de curta duração, como evidenciado pelos baixos títulos de anticorpos aglutinantes e neutralizantes em bovinos vacinados (Fig.1 e 2), dados que concordam com os trabalhos de Marshal et al. (1979) e Bolin et al. (1989).

Outros fatores que podem influenciar a eficácia das vacinas são os esquemas de vacinação empregados, a qualidade e a quantidade de microrganismos imunizantes (Bey \& Johnson 1986), grau de semelhança antigênica entre os antígenos que compõem a bacterina, tipo de adjuvante utilizado, temperatura de conservação, $\mathrm{pH}$, inocuidade inespecífica, potência, esterilidade e transporte da vacina até a propriedade (Arduino et al. 2004, Arduino 2005, Machado et al. 2007).

A modificação da concentração do antígeno, adjuvante, formulação vacinal ou o modo de preparação do antígeno pode aumentar a efetividade destas vacinas. Futuras modificações no regime de vacinação podem acarretar num aumento da proteção conferida por estes produtos, entretanto é improvável que uma vacina com menos de seis meses de duração de imunidade seja prática para o uso na produção animal (Bolin et al. 1989).

Todos os animais que receberam doses de vacina produziram médias de títulos superiores no ELISA e SAM quando utilizada a amostra Hardjo-bovis como antígeno. Provavelmente, isto tenha ocorrido devido ao fato desta amostra possuir maior expressão de antígenos de superfície imunogênica (membrana externa) em termos quantitativos em relação às duas outras amostras, fato que já havia sido comprovado anteriormente por Bolin et al. (1989) quando utilizaram as amostras Hardjoprajitino e Hardjobovis em vacinas diferentes mensurando as respostas de anticorpos aglutinantes e neutralizantes individualmente.

Segundo Huhn et al. (1970), os resultados encontrados a partir de testes de potência realizados em hamsters demonstram haver respostas pouco duradoras a partir de soros obtidos de bovinos imunizados. Segundo estes autores, as respostas frequentemente são inferiores há dois meses. Este fato é um forte indicativo de que a imunidade duradoura, capaz de impedir a leptospirose renal, pode não ocorrer nestas vacinas destinadas aos bovinos, pois a leptospiremia precede a infecção renal. Estes resultados são de extrema relevância e devem ser levados em consideração, pois todos os resultados demonstraram uma imunidade por um breve período de tempo o que leva a inferir que, provavelmente, todas as vacinas utilizadas não impediriam o estabelecimento do estado de portador renal.

Vacinas de células inteiras são difíceis de serem avaliadas quantitativamente para a potência imunogênica. Embora o número de células presentes poder ser conhecido, a relação entre o número de células e a massa celular nem sempre é constante; pois uma quantidade desconhecida de antígeno de células de Leptospira spp. é liberada dentro dos meios de cultura e todas as vacinas contêm este meio tanto quanto células (Bey et al. 1974).

A centrifugação e a lavagem destas células são utilizadas na preparação da vacina para remover quantidades grosseiras de meio de cultura. A liofilização do produto final e sua padronização com uma quantidade definida melhoram substancialmente o poder imunogênico destas vacinas quando comparados com os resultados de vacinas utilizando membrana externa em sua constituição (Bey et al. 1974, Nardi Júnior et al. 2007).

Além disso, a escala de produção em termos quantitativos demonstrou ser importante, pois grandes volumes podem limitar o crescimento destes microrganismos, estabelecido um volume de 100 litros, volume efetivo, para a fermentação com um fluxo de ar de $10 \mathrm{~L} / \mathrm{min}(0,01 \mathrm{vvm})$ e sem agitação mecânica, aumentou a escala de produção no processo de fermentação proporcionando benefícios econômicos significativos na produção de vacina anti-Leptospira spp. (Zamora et al. 2005).

Durante o processo de fabricação, as amostras de isolados locais devem ser estocadas em nitrogênio líquido para a utilização na fabricação de vacinas. Além disso, os lotes de sementes devem ser fracionados em diferentes amostras e várias alíquotas, além de serem reativadas em modelos animais antes de serem congeladas (Palit et al. 1996). Segundo Palit et.al. (1996), há uma maior eficiência destas amostras, incluindo a Hardjo, em testes de potência em relação a uma bacterina comercial utilizando o modo tradicional de fabricação da vacina contra leptospirose, fato que pôde ser inferido na atual investigação. Provavelmente, as amostras utilizadas perderam sua antigenicidade, sendo que os fabricantes poderiam mantê-las congeladas para obterem um produto de maior antigenicidade (Maura et al. 2006). 
Estes resultados sugerem que os títulos desenvolvidos entre as bacterinas não foram homogêneos e as bacterinas polivalentes produziram resposta de curta duração exigindo revacinações em períodos inferiores há seis meses. Duas das vacinas avaliadas não produziram resposta significativa na maior parte do tempo provavelmente pela baixa concentração celular ou mesmo ausência do antígeno da sorovariedade Hardjo em sua composição. A vacina monovalente com quantidade celular controlada produziu resultados superiores em relação às vacinas comerciais.

Agradecimentos.- R.O. Rodrigues, A.P. Lage e E.C. Moreira são bolsistas do Conselho Nacional de Desenvolvimento Científico e Tecnológico (CNPq), Brasília.

\section{REFERÊNCIAS}

Araújo V.E.M., Moreira E.C., Naveda L.A.B., Silva J.A. \& Contreras R.L. 2005. Freqüência de aglutininas anti-Leptospira interrogans em soros sangüíneos de bovinos, em Minas Gerais, de 1980 a 2002. Arq. Bras. Med. Vet. Zootec. 57(4):430-435.

Arduino G.G.C. 2005. Títulos de anticorpos aglutinantes induzidos por vacinas comerciais contra leptospirose bovina. Tese de Doutorado em Medicina Veterinária Preventiva, Faculdade de Ciências Agrárias e Veterinárias, Universidade Estadual Paulista, Jaboticabal, SP. 115p.

Arduino G.G.C., Girio R.J.S., Freire M.M. \& Filho M.M. 2004. Anticorpos contra Leptospira spp em bovinos leiteiros vacinados com bacterina polivalente comercial: perfil sorológico frente a dois esquemas de vacinação. Ciência Rural 34(3):865-871. 2

Arduino G.G.C., Girio R.J.S., Magajevski F.S. \& Pereira G.T. 2009. Títulos de anticorpos aglutinantes induzidos por vacinas comerciais contra leptospirose bovina. Pesq. Vet. Bras. 29(7):575-582.

Avrameas S. \& Ternynck T. 1971. Peroxidase labeled antibody and Fab conjugates with enhanced intracellular penetration. Immunochemistry 8:1175-1179.

Bey R.F. \& Johnson R.C. 1986. Current status of Leptospiral vaccines. Progr. Vet. Microbiol. Immun. 2:175-197.

Bey R.F., Auran N.E. \& Johnson R.C. 1974. Immunogenicity of whole cell and outer envelope leptospiral vaccines in hamsters. Infect. Immun. 10(5):1051-1056.

Bolin C.A., Zuerner R.L. \& Trueba G. 1989. Effect of vaccination with a pentavalent leptospiral vaccine containing Leptospira interrogans serovar Hardjo type Hardjo-bovis on type Hardjo-bovis infection of cattle. Am. J. Vet. Res. 50(12):2004-2008.

Bolin C.A., Phil J.A.C., Zuerner R.L. \& Trueba G. 1991. Effect of vaccination with a monovalent Leptospira interrogans serovar hardjo type Hardjo-bovis vaccine on type Hardjo-bovis infection of cattle. Am. J. Vet. Res. 52(10):1639-1643.

Brod C.S., Martins L.F.S., Nussbaum J.R., Fehlberg M.F.B., Furtado L.R.I. \& Rosado R.L.L. 1995. Leptospirose bovina na região sul do Estado do Rio Grande do Sul. Hora Vet. 14:15-20.

Chiareli D., Moreira E.C., Gutierrez H.O.D., Rodrigues R.O., Marcelino A.P., Meneses J.N.C. \& Almeida V.M.A. 2008. Freqüência de aglutininas anti-Leptospira interrogans em eqüídeos, em Minas Gerais, 2003 a 2004. Arq. Bras. Med. Vet. Zootec. 60(6):15761579.

Cole J.R., Sulzer C.R. \& Pursell A.R. 1973. Improved microtechnique for the leptospiral microscopic agglutination test. Appl. Microbiol. 25(6):976-980.

Cordeiro F., Guida H.G., Ramos A.A. \& Mendoza T.R. 1975. Aglutininas anti-leptospira em soros de bovinos do estado do Rio de Janeiro. Pesq. Agropec. Bras., Sér. Vet. 10(8):9-19.
Cortez A., Castro A.M.G., Heinemann M.B., Soares R.M., Leite R.C., Scarcelli E., Genovez M.E., Alfieri A.A. \& Richtzenhain L.J. 2006. Detecção de ácidos nucléicos de Brucella spp., Leptospira spp., herpesvirus bovino e vírus da diarréia viral bovina, em fetos abortados e em animais mortos no perinatal. Arq. Bras. Med. Vet. Zootec. 58:1226-1228.

Doria J.D., Viegas S.A.R., Viegas E.A., Virgens N.C. \& Santos N.M. 1982. Estudo sorológico sobre a leptospirose em bovinos no estado da Bahia, 1977. Arqs Esc. Med. Vet. UFBA 7(1):105-113.

Ellinghausen H.C. Jr, McCullough W.G. 1965. Nutrition of Leptospira pomona and growth of 13 other serotypes: A serum-free medium employing oleic albumin complex. Am. J. Vet. Res. 26:39-44.

Enrique K.F., Zamora J.D.B., Gutiérrez R.B.,Torres F.H., Airado J.L. \& Hernández 2005. Empleo de la diafiltración en el lavado de cultivos de Leptospira interrogans canicola canicola para la producción de la vacuna vax-Spiral. Revta Cubana Med. Trop. 57(1):6970.

Faine S., Adler B., Bolin C. \& Perolat P. 1999. Leptospira and Leptospirosis. $2^{\text {nd }}$ ed. Medisci, Melbourne. 272p.

Favero A.C.M., Mangerona A.C.S., Alessi L.J., Morais Z.M., Pinheiro S.R., Ferreira Neto J.S. \& Vasconcellos S.A. 1997. Aglutininas pósvacinais em bovinos imunizados com bacterina tetravalente contra a leptospirose: influência de reações pré-vacinais, homólogas e heterólogas. Arqs Inst. Biológico, São Paulo, 64(2):45-55.

Favero M., Pinheiro S.R., Vasconcellos S.A., Morais Z.M., Ferreira F. \& Ferreira Neto J.S. 2001. Leptospirose bovina: variantes sorológicas predominantes em colheitas efetuadas no período de 1984 a 1997 em rebanhos de 21 estados do Brasil. Arqs Inst. Biológico, São Paulo, 68(2):29-35.

Favero A.C.M., Pinheiro S.R., Vasconcellos S.A., Morais Z.M., Ferreira F. \& Ferreira Neto J.S. 2002. Sorovares de leptospiras predominantes em exames sorológicos de bubalinos, ovinos, caprinos, eqüinos, suínos e cães de diversos Estados brasileiros. Ciência Rural 32(4):613-619.

Galton M.M., Sulzer C.R., Santarosa C.A. \& Fields M.J. 1965. Application of a microtechnique to the agglutination test for leptospiral antibodies. Appl. Microbiol. 13:81-85.

Giorgi W., Teruya J.M., Silva A.S. \& Genovez M. 1981. Leptospirose: resultados das soroaglutinações realizadas no Instituto Biológico de São Paulo, durante os anos de 1974 a 1980. Biológico, São Paulo, 47:299-309.

Hanson L.E. 1997. Immunology of bacterial diseases, with special reference to leptospirosis. J. Am. Vet. Med. Assoc. 170(9):991-994.

Hanson L.E., Tripathy D.N. \& Killinger A.H. 1972. Current status of Leptospiorosis immunization in swine and cattle. J. Am. Vet. Med. Assoc. 161(11):1235-1242.

Herrmann G.P., Lage A.P., Moreira E.C., Haddad J.P.A., Resende J.R., Rodrigues, R.O. \& Leite R.C. 2004. Soroprevalência de aglutininas anti-Leptospira spp. em ovinos nas Mesorregiões Sudeste e Sudoeste do Estado Rio Grande do Sul, Brasil. Ciência Rural 34(2): 443-448.

Homem V.S.F., Heinemann M.B., Morais Z.M., Vasconcellos S.A., Ferreira F. \& Ferreira Neto J.S. 2001. Estudo epidemiológico da leptospirose bovina e humana na Amazônia Oriental brasileira. Revta Soc. Bras. Med. Trop. 34(2):173-180.

Huhn R.G., Claus K.D. \& Macheak M.E. 1970. Vaccination of cattle with Leptospira pomona bacterins. II. Potency assay using the hamster passive protection test. Proc. $74^{\text {th }}$ Annu. Meet. U.S. Anim. Health Assoc., p.178-196.

Lage A.P., Leite R.M.H., Thompson J.A., Bandeira D.A., Herrmann G.P., Moreira E.C. \& Gonçalves V.S.P. 2007. Serology for Leptospira sp. in cattle of the State of Paraíba, Brazil. Arqs Inst. Biológico, São Paulo, 74(3):185-190.

Levett P.N. 2001. Leptospirosis. Clin. Microbiol. Rev. 14(2):296-326. 
Lilenbaum W. \& Santos M.R.C. 1996. Effect of management systems on the prevalence of bovine leptospirosis. Vet. Rec. 138(23):570-571.

Lowry O.H., Rosebrough N.J., Farr A.L. \& Randall R.J. 1951. Protein measurement with the Folin phenol reagent. J. Biol. Chem. 193:265275.

Maura R.B., Rodriguesz A.G., Sardiñas C.P., Santiesteban N.B. \& Abreu Y.V. 2006. Conservación de cepas vacunales de Leptospira a $-70^{\circ} \mathrm{C}$. Revta Cubana Med. Trop. 58(1):50-55.

Marshall R.B., Broughton E.S. \& Hellstrom J.S. 1979. Protection of cattle against natural challenge with Leptospira interrogans serovar hardjo using a hardjo-pomona vaccine. N. Z. Vet. J. 27(6):114-116.

Machado M., Mahy T., Pérez E., Noroña M., Fajardo E.M. \& Izquierdo L. 2007. Estudios de estabilidad de vida de estante en condiciones de estrés de la vacuna antileptospirósica vax-Spiral ${ }^{\circledR}$. VacciMonitor 16(1):1-4

Manual of Standards for Diagnostic Test and Vaccines 2001. Leptospirosis. World Organization for Animal Health, Paris, p.198217.

Moreira E.C. 1994. Avaliação de métodos para erradicação de leptospiroses em bovinos leiteiros. Minas Gerais, Brasil. Tese de Doutorado em Medicina Veterinária Preventiva, Escola de Veterinária, Universidade Federal de Minas Gerais, Belo Horizonte. 94p.

Moreira E.C., Silva J.A., Viana F.C., Santos W.L., Anselmo F.P. \& Leite R.C. 1979. Leptospirose bovina I. Aglutininas anti-leptospiras em soros sanguíneos de bovinos de Minas Gerais. Arqs Esc. Vet. UFMG 31(3):375-378.

Nardi Júnior G., Genovez M.E., Ribeiro M.G., Castro V. \& Jorge A.M. 2007. Interference of vaccinal antibodies on serological diagnosis of leptospirosis in vaccinated buffalo using two types of commercial vaccines. Braz. J. Microbiol. 38:363-368.

Oliveira S.J. 1977. Presença de aglutininas anti-leptospira em suínos e bovinos, com e sem sinais de infecção no Rio Grande do Sul. Bolm Inst. Pesq. Vet. Desidério Finamor 4:57-64.

Palit A., Alexander A.M., Slacek B. \& Taylor C. 1996. The efficacy of Leptospira interrogans serovars pomona and copenhageni and Leptospira borgpeternsii serovar Hardjo vaccine in cattle. N. Z. Vet. J. 44(2):64-66.

Sampaio I.B.M. 1998. Estatística Aplicada à Experimentação Animal. Fundação de Ensino e Pesquisa em Medicina Veterinária e Zootecnia, Belo Horizonte. 221 p.

Siddique I.H. \& Shah S.M. 1990. Evaluation of polyvalent leptospiral vaccine in hamsters. Indian Vet. J. 67:1006-1010.

Srivastava S.K. 2006. Prospects of developing leptospiral vaccines for animals.Indian J. Med. Microbiol. 24(4):331-336.

Tabata R., Neto H.S., Zuanaze M.A.F., Oliveira E.M.D., Dias R.A., Morais Z.M., Ito F.H. \& Vasconcelos S.A. 2002. Cross neutralizing antibodies in hamsters vaccinated with leptospiral bacterins produced with three serovars of serogroup Sejroe. Braz. J. Microbiol. 33(3):265-268.

USAH 1976. Internal Reference Guide for Potency Assay of Leptospirose interrogans serotype grippotyphosa bacterins, USDA Veterinary Services, lowa. 12p.

Vasconcellos S.A., Barbarini Júnior O., Umehara O., Morais Z.M., Cortez A., Pinheiro S.R., Ferreira F., Fávero A.C.M. \& Ferreira Neto J.S. 1997. Leptospirose bovina: níveis de ocorrência e sorotipos predominantes em rebanhos dos Estados de Minas Gerais, São Paulo, Rio de Janeiro, Paraná, Rio Grande do Sul e Mato Grosso do Sul. Arqs Inst. Biológico, São Paulo, 64(2):7-15.

Zamora J.D.B., Enrique K.F., Boué R.G., Torres F.H., Airado J.L. \& Hernández D.R. 2005. Escalado de la fermentación de Leptospira interrogans canicola para la producción de la vacuna vax-Spiral. Revta Cubana Med. Trop. 57(1):71-72. 